\title{
Clinical and Etiological Study on Chronic Liver Diseases
}

\author{
Sudeshna Mallik ${ }^{1}$, Kumkum Sarkar ${ }^{2}$, Mehebubar Rahman $^{3}$, Soumendra Nath Haldar ${ }^{4}$ \\ ${ }^{1}$ Associate Professor, ${ }^{2}$ Assistant Professor, ${ }^{3}$ Associate Professor, ${ }^{4}$ Assistant Professor, Department of Tropical Medicine, \\ School of Tropical Medicine, Kolkata, India
}

Corresponding author: Kumkum Sarkar, School of Tropical Medicine, Kolkata; 108, C R Avenue, Kolkata -700073, India

DOI: $10.21276 / \mathrm{ijcmsr} .2018 .3 .2 .19$

How to cite this article: Sudeshna Mallik, Kumkum Sarkar, Mehebubar Rahman, Soumendra Nath Haldar. Clinical and etiological study on chronic liver diseases. International Journal of Contemporary Medicine Surgery and Radiology. 2018;3(2):B77-B80.

\section{A B S T R A C T}

Introduction: Chronic liver disease (CLD) with its different aetilogy and presentation is a very common cause of hospital admission in tropical country. This study on CLD includes the diagnosis of aetiology and examination of clinical features as well as detection of associated disease and complications. Aim of the study was to detect the aetiological factors of CLD in and around Calcutta and to study clinical, biochemical, ultrasonographic, endoscopic and histopathological features of different CLD.

Material and Methods: This was an observational study conducted on consecutive 35 patients with CLD attending OPD as well as inpatients in CSTM at the School of Tropical Medicine, Kolkata within one year period. In our single centre, prospective, observational study, 35 consecutive patients with CLD were included. Chronic liver disease (CLD) was diagnosed on the basis of clinical findings, laboratory investigations, ultrasonographic and upper $\mathrm{Gl}$ endoscopic study.

Results: Fatigue was the commonest symptom (85.71\%). Majority of patients (70\%) presented with hepato-splenomegaly with or without jaundice $(42.86 \%)$. About half of the patients presented with ascites. About $1 / 3^{\text {rd }}$ of the patients had history of alcoholism or blood transfusion. Raised SGPT was the commonest (83.09\%) and most reliable marker of chronic hepatitis. Ultrasonography and upper gastrointestinal endoscopy both helped in the diagnosis of portal hypertension (42.85\%). Needle liver biopsy could be done in 11 cases only. Chronic active and chronic persistant hepatitis were found in 3 cases each and 2 idiopathic portal hypertension/ NCPF (non cirrhotic portal fibrosis) diagnosed in 1 case. Liver biopsy was helpful in diagnosing rare causes of hepatomegaly like amyloidosis (1 case) and chronic granulomatous hepatitis ( 2 cases) in our study. Conclusion: From our study it can be concluded that clinic-aetiological spectrum of CLD can be devided into five major groups - chronic hepatitis, non cirrhotic portal fibrosis, space occupying lesions, metabolic liver disease and chronic granulomatous hepatitis.

Key words: Chronic liver diseases, clinical presentation, etiology

\section{INTRODUCTION}

Spectrum of chronic liver disease extends from chronic hepatitis to cirrhosis and finally to hepato-cellular carcinoma. Most cases of chronic hepatitis in tropical countries result from Hepatitis B virus and Hepatitis c virus infection. Other forms of CLD include: those resulting from excessive alcohol intake, Indian childhood cirrhosis, Wilson's disease, Haemosiderosis and veno-occlusive disease. ${ }^{1}$ Haemosiderosis or Bantu's siderosis is the diseasae of south Africa, whereas veno-occlusive disease occurs in Jamaica and other localized part of Africa. Liver is rarely involved in other chronic infective diseases like TB, Histoplasmosis and others. ${ }^{1}$ Major space occupying lesions involving liver are Amoebic abscess, pyogenic abscess and hydatid disease.

Chronic hepatitis is defined as chronic inflammatory reaction within the liver continuing without improvement for atleast 6 months. $^{2}$ However, where the diagnosis is obvious as in autoimmune hepatitis, it is not necessary to wait for 6 months before commencing therapy. Rangari $\mathrm{M}$ et $\mathrm{al}^{3}$ also noted that the criteria of duration of 6 months should not be applied to an individual patient presenting with shorter clinical course, who otherwise has otherwise has other features of chronic liver disease.

Dienstag and Issel-becher described the aetiology of chronic hepatitis as viral hepatitis $\mathrm{B}, \mathrm{C}$ and $\mathrm{D}$, Autoimmune hepatitis, drug associated hepatitis, cryptogenic hepatitis. According to Sheila Sherlock hepatitis B and C, Autoimmune hepatitis and Wilson's disease are main causes of chronic hepatitis. A recent study carried out at New Delhi ${ }^{4}$ has showed aetiology of cirrhosis of liver in the young and adult groups as $\mathrm{HBV}$ related (50\% in both), alcohol related (6\% and $25 \%$ ), cryptogenic (30\% and 20\%). In the young group one had Wilson's disease and another had alpha 1-antitrypsin deficiency.

Regarding autoimmune hepatitis 76 the prominence of extrahepatic features of auto-immunity as well as seroimmunologic abnormalities (ANA, SMA, LKMs) supports an autoimmune process in its pathogenesis. But these typical features of autoimmunity do not occur in all cases. So broader designation idiopathic or cryptogenic is used. ${ }^{5}$ 
Many drugs produce abnormalities in liver function test (LFT) without progressive liver disease, but some drugs can elicit an adverse reaction indistinguishable from autoimmune hepatitis. drugs having definite association with chronic active hepatitis (C.A.H) are oxyphenisatin, methyldopa, nitrofurantoin, dantrolene sodium. Isoniazid has probable association with C.A.H. drugs having rare association with C.A.H. are acetaminophen, halothane, sulfonamide, aspirin. Chronic hepatitis can also be classified by ${ }^{6}$

1. Grade of necro-inflammatory activity.

2. Stage of fibrosis, cirrhosis based on histopathologic examination of liver tissue.

Present study was undertaken to find out the causes of CLD and its various clinical presentations in our geographical region and compare them with findings of past workers of differ regions.

\section{MATERIAL AND METHODS}

This was an observational study conducted on consecutive 35 patients with CLD attending OPD as well as inpatients in CSTM at the School of Tropical Medicine, Kolkata within one year period. The patients were selected irrespective of their age and sex. Chronic liver disease (CLD) was diagnosed on the basis of clinical findings, laboratory investigations, ultrasonographic and upper GI endoscopic study. Liver biopsy was also done, where it was possible. Inclusion criteria for this study were hepato/hepatosplenomegaly with abnormal LFT for more than 6 months, chronic viral hepatitis, acute hepatitis- whose clinical feature and LFT not resolving within 6 months, follow up patients with biopsy proven CLD, patients with recurrent jaundice for last 6 months and patients with unexplained hepatomegaly. A pre-designed proforma was used to collect data by proper history taking, clinical examination and investigations of total 35 patients with CLD. Apart from routine investigations, viral markers (HBsAg, $\mathrm{HBeAg}$, Anti $\mathrm{HBc}$, Anti $\mathrm{HCV}$ ), autoimmune markers (ANA, LE cell phenomenon), prothombin time, upper GI endoscopy, slit lamp examination of eye, serum ceruloplasmin, and liver biopsy were done. Liver biopsy were not done in all patients due to presence of either ascites or hepatocellular decompensation or raised prothombin time or presence of SOL in the liver.

\section{STATISTICAL ANALYSIS}

Descriptive statistical method was used for data analysis with the help of Microsoft office 2007.

\section{RESULTS}

We have studied 35 patients of CLD in one year period. Their clinical profile were observed in detail along with laboratory investigations to reach clinic aetiological diagnosis. Common age group was from 11 to 20 years. Majority (80\%) were below 50 years.

Majority of patients (68.57\%) were male with male:female $=2.2: 1$ (figure-1).

Fatigue was the commonest symptom (85.71\%). Other common symptoms of CLD were found to be pain/ heaviness of abdomen, loss of appetite, nausea, vomiting, loss of weight, fever and hematemesis-melena in order of frequency. Most commonly found duration of illness was 6-12 months. Majority of patients (approximately 70\%) presented with hepato-splenomegaly with or without

\begin{tabular}{|l|c|c|}
\hline Symptoms, sign & $\begin{array}{c}\text { Number of } \\
\text { Patients }\end{array}$ & Percentage \\
\hline Fever & 14 & $40 \%$ \\
\hline Fatigue & 30 & $85.71 \%$ \\
\hline Loss of appetite & 22 & $62.86 \%$ \\
\hline Loss of weight & 17 & $48.57 \%$ \\
\hline Nausea, vomiting & 17 & $48.57 \%$ \\
\hline Pain abdomen, heaviness & 28 & $80 \%$ \\
\hline Haematemesis, melaena & 7 & $20 \%$ \\
\hline Anaemia & 22 & $62.86 \%$ \\
\hline Jaundice & 15 & $42.86 \%$ \\
\hline Oedema & 8 & $22.86 \%$ \\
\hline Clubbing & 5 & $14.29 \%$ \\
\hline Hepatomegaly & 25 & $71.43 \%$ \\
\hline Splenomegaly & 26 & $74 \%$ \\
\hline Ascites & 16 & $45.71 \%$ \\
\hline Engorged abdominal vein & 5 & $14.29 \%$ \\
\hline \multicolumn{2}{|c|}{ Table-1: Presenting sign and symptoms of CLD } \\
\hline
\end{tabular}

\begin{tabular}{|c|l|c|c|}
\hline \multicolumn{2}{|l|}{ Clinico-pathological spectrum } & $\begin{array}{c}\text { No. of } \\
\text { cases }\end{array}$ & Percentage \\
\hline 1. & Chronic hepatitis/ cirrhosis & 26 & $74.25 \%$ \\
\hline 2. & $\begin{array}{l}\text { Non cirrhotic portal fibrosis } \\
\text { (NCPF)/ Idiopathic portal } \\
\text { hypertension }\end{array}$ & 2 & $5.7 \%$ \\
\hline 3. & Chronic granulomatous hepatitis & 2 & $5.7 \%$ \\
\hline 4. & $\begin{array}{l}\text { Space occupying lesions } \\
\text { i. Amoebic liver abcess }\end{array}$ & 2 & $5.7 \%$ \\
& ii. Hydatid cyst & 1 & $2.86 \%$ \\
\hline 5. & $\begin{array}{l}\text { Metabolic liver disease } \\
\text { i. Wilson's disease } \\
\text { ii. Amyloidosis }\end{array}$ & 1 & $2.86 \%$ \\
\hline \multicolumn{2}{|l|}{ Table-2: Clinico-pathological spectrum of CLD } \\
\multicolumn{2}{|c|}{} \\
\hline
\end{tabular}

\begin{tabular}{|c|c|c|c|}
\hline \multicolumn{2}{|c|}{ Etilogy } & \multirow{2}{*}{$\begin{array}{c}\text { No. of cases } \\
12 \\
4 \\
1\end{array}$} & \multirow[b]{2}{*}{$\begin{array}{c}\text { Percentage } \\
34.29 \% \\
11.43 \% \\
2.86 \%\end{array}$} \\
\hline 1. & $\begin{array}{l}\text { Viral hepatitis } \\
\text { i. Hepatitis B } \\
\text { ii. Hepatitis C } \\
\text { iii. Hepatitis B + C }\end{array}$ & & \\
\hline 2. & Alcoholic & 3 & $8.57 \%$ \\
\hline 3. & $\begin{array}{l}\text { Hepatotoxic agents } \\
\text { i. Drugs } \\
\text { ii. Arsenic }\end{array}$ & $\begin{array}{l}2 \\
1\end{array}$ & $\begin{array}{c}5.7 \% \\
2.86 \%\end{array}$ \\
\hline 4. & $\begin{array}{l}\text { Infections other than virus } \\
\text { i. Tuberculosis } \\
\text { ii. Amoebiasis } \\
\text { iii. Hydatid disease }\end{array}$ & $\begin{array}{l}1 \\
2 \\
1\end{array}$ & $\begin{array}{c}2.86 \% \\
5.7 \% \\
2.86 \% \\
\end{array}$ \\
\hline 5. & $\begin{array}{l}\text { Metabolic liver disease } \\
\text { iii. Wilson's disease } \\
\text { iv. Amyloidosis }\end{array}$ & $\begin{array}{l}1 \\
1\end{array}$ & $\begin{array}{l}2.86 \% \\
2.86 \%\end{array}$ \\
\hline 6. & $\begin{array}{l}\text { Combination } \\
\text { i. Alcohol + HCV } \\
\text { ii. Drug + HBV }\end{array}$ & $\begin{array}{l}1 \\
1\end{array}$ & $\begin{array}{l}2.86 \% \\
2.86 \%\end{array}$ \\
\hline 7. & Cryptogenic & 11 & $31.43 \%$ \\
\hline & Table-3: Etilog & spectrum of $\mathrm{C}$ & \\
\hline
\end{tabular}




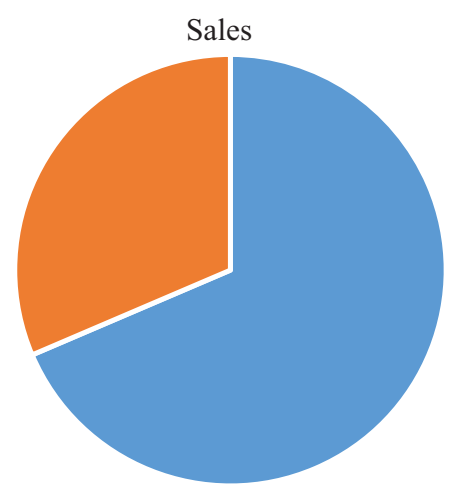

Male Female

Figure-1: Pie chart showing gender distribution

jaundice (42.86\%). Common physical signs found were hepatomegaly, splenomegaly, anemia and jaundice. About half of the patients presented with ascites and quarter of the patients were presented with edema (table-1).

About $1 / 3^{\text {rd }}$ of the patients had history of alcoholism or blood transfusion. Elevation of SGPT was found to be commonest (83.09\%) and most reliable marker of chronic hepatitis. Albumin-globulin ratio was changed $(<1.5)$ in almost all cases (94.29\%). Serum bilirubin level and serum alkaline phosphatase levels were elevated in about half of the cases.

Ultrasonography and upper gastrointestinal endoscopy both helped in the diagnosis of portal hypertension (42.85\%). About $1 / 3^{\text {rd }}$ of patients had raised prothrombin time which reflected chronic hepato-cellular failure. Needle liver biopsy could be done in 11 cases only, which showed showed cirrhosis none. Chronic active and chronic persistant hepatitis were found in 3 cases each and 2 idiopathic portal hypertension/ NCPF (non cirrhotic portal fibrosis) diagnosed in 1 case. Liver biopsy was helpful in diagnosing rare causes of hepatomegaly like amyloidosis (1 case) and chronic granulomatous hepatitis ( 2 cases) in our study.

From our study it can be concluded that clinico-pathological spectrum of CLD can be devided into five major groups - chronic hepatitis, non cirrhotic portal fibrosis, space occupying lesions, metabolic liver disease and chronic granulomatous hepatitis. Among them chronic hepatitis was commonest presentation (72.45\%) (table-2). One patient of Wilson's disease although presented with clinical features of chronic hepatitis/ cirrhosis, was included in the metabolic liver disease group.

About half of the patients had evidence of hepatitis B virus infection, hepatitis $\mathrm{C}$ infection was $15.38 \%$ cases and hepatitis $\mathrm{B}$ coinfection with hepatitis $\mathrm{C}$ was found only $3.85 \%$ cases. Alcoholic chronic hepatitis was found in $10 \%$ cases, wilson's disease and hepatotoxic drugs as etiological factors were rare. In $1 / 3^{\text {rd }}$ cases no definitive diagnosis (cryptogenic) could be made. Other causes were amoebic liver abcess, hydatid cyst, amyloidosis and chronic arsenic toxicity. Out of $2 \mathrm{NCPF}$ cases 1 was related to chronic arsenic toxicity and out of 2 granulomatous hepatitis 1 was related to tuberculosis. We could not found any definitive cause in 11 patients. Among them 9 presented with features of chronic hepatitis, 1 with granulomatous hepatitis and 1 with NCPF (table-3).

In contrast to Western country hepatitis virus infection is found to be the chief offender in the causation of chronic liver diseases till date. Tough cryptogenic group still comprise the major etiologic group in CLD which may shrink if hepatitis $B$ virus mutant and hepatitis $C$ virus antibody were traced more widely.

\section{DISCUSSION}

35 patients with CLD were studied. The mean age of the patients was $32.29 \pm 14.72$ years. Commonest age group was 11 to 20 years. They had mostly idiopathic and chronic hepatitis B. We found 2 patients of amoebic liver abscess belong to $40-60$ years. This age group is quite similar to that found by Michael J. G. et al who had found the amoebic liver abscess was 10 times more frequent in adult males than in females. ${ }^{7}$ Common physical signs found were hepatomegaly, splenomegaly, anemia and jaundice. About half of the patients presented with ascites. This finding also corroborates with Sama et $\mathrm{al}^{8}$ who found ascites in $40 \%$ cases.

Among 35 patients 26 were diagnosed to be suffering from chronic hepatitis/ cirrhosis on the basis of clinical laboratory investigations, ultrasonographic, upper GI endoscopic study and histopathological methods. This is the major group of CLD in Tropics (74.25\%). 12 patients (46.15\%) were HBV related, 4 patients (15.38\%) were HCV related and 1 patients (3.84\%) had evidence of infection of both viruses. 1 patients (3.84\%) had evidence of pre- core mutant HBV infection. Our study corroborates well with that of Ray G. et $\mathrm{al}^{9}$ from Eastern India. In India HBV is reported to be responsible for $70 \%$ cases of chronic hepatitis. ${ }^{10}$ The relation is found to be much more than that found in our study but coinfection of $\mathrm{HBV}$ and $\mathrm{HCV}$ is uncommon and has been recorded in less than $10 \%$ of chronic hepatitis patients. ${ }^{10}$ This finding support our observation (3.8\%).

Data regarding prevalence of dual infection of $\mathrm{HBV}$ and $\mathrm{HCV}$ in CLD in India raises much controversy. Sarin et $\mathrm{al}^{11}$ demonstrated dualinfection in $13.5 \%$ cases while Tandon et $\mathrm{al}^{12}$ recorded $\mathrm{HBV}$ and $\mathrm{HCV}$ co-infection and superinfection in $75 \%$ and $42 \%$ respectively to chronic hepatitis.

Our study also correlate with Amrapurkar et $\mathrm{al}^{13}$ who showed that $\mathrm{HbsAg}$ was positive in $40.5 \%$ and $\mathrm{Anti} \mathrm{HCV}$ was positive in $16.6 \%$ cases of CLD but Sood $\mathrm{A}$ et $\mathrm{al}^{10}$ reported that in CLD, incidence of $\mathrm{HCV}$ was apparently higher as compared to HBV (25.9\% vs. $18.8 \%)$ and combined infection. Though authors could not rule out the false positivity of Anti HCV reactivity by ELISA.

We found alcoholic chronic hepatitis in 3 patients (11.59\%). Wilson's disease (only 1 case) and hepatotoxic drugs (only 2 cases) as etiological factors were rare. Autoimmunity was found in none. This findings was also supported by Ray $G$ et al. ${ }^{9}$

\section{Limitations}

This study has several limitations. We could not test HBV DNA and HCV RNA of all patients as CLD may not show positive $\mathrm{HBsAg}$ and Anti $\mathrm{HCV}$. We could not perform all autoimmune serology tests and liver biopsy in all patients.

\section{CONCLUSION}

This study offers data on clinical presentation and the etiology of chronic liver disease in the Eastern part of India. From our 
study it can be concluded that clinic-aetiological spectrum of CLD can be devided into five major groups - chronic hepatitis, non cirrhotic portal fibrosis, space occupying lesions, metabolic liver disease and chronic granulomatous hepatitis.

\section{ACKNOWLEDGMENTS}

I am thankful to Prof. Nandita Basu, Director, School of Tropical Medicine, Kolkata, for allowing me to work in this institution and extending valuable help when needed. I must express my deepest gratitude to Dr. B. Saha, Professor and H.O.D. of Department of Tropical Medicine and to Prof. R. P. Goswami of Department of Tropical Medicine, School of Tropical Medicine, Kolkata.

\section{REFERENCES}

1. G. C. Cook: Tropical Gastroenterological problems, In Manson's Tropical diseases, Editor, Gordon Cook, 22 ${ }^{\text {nd }}$ edition: 2009; 129-136.

2. https://en.wikipedia.org/wiki/Chronic_liver_disease accessed on 11/04/2018.

3. Rangari M, SR Agarwal, Sarin SK: Chronic hepatitis, in Postgraduate Medicine, Vol. 14, 2000 (Millennium CMF) Editor Dr. Siddhartha N. Shah, 2000, pp. 43346.

4. Sarin SK, Chari S, Sundaram KR, Ahuja RK, Anand BS, Broor SL. Young v adult cirrhotics: a prospective, comparative analysis of the clinical profile, natural course and survival. Gut. 1988;29(1):101-7.

5. Kasper, Fauci, Hauser, Longo, Jameson, Loscalzo, Harrison's Principals of Internal Medicine: Chronic hepatitis, disorder of gastrointestinal system, $19^{\text {th }}$ edition, vol-2, 2049-2052.

6. Desmet VJ, Gerber M, Hoofnagle JH, Manns M, Scheuer PJ. Classification of chronic hepatitis: diagnosis, grading and staging. Hepatology. 1994;19(6):1513-20.

7. Manson's Tropical diseases, $12^{\text {th }}$ edition pp. 1255-1298.

8. Sama SK, Bhargava S, Gopi Nath N et al. Noncirrhotic portal fibrosis. Am J Med 1971;51(5): 160-169.

9. Ray $\mathrm{G}^{1}$, Ghoshal UC, Banerjee PK, Pal BB, Dhar K, $\mathrm{Pal}$ AK, Biswas PK. Aetiological spectrum of chronic liver disease in eastern India. Trop Gastroenterol. 2000;21(2):60-2.

10. A Sood a, Sidhu SS, Vandana Midha, Divya Jyoti. High Seroprevalence of Hepatitis C Virus and Dual Infection (Hepatitis B and C Virus) in Non-Alcoholic Chronic Liver Disease in North India. JAPI. 1999;47(4):205-8.

11. Sarin SK, Gupta RC, Banerjee K, Khandekar P: How prevalence of hepatitis $\mathrm{C}$ viral infection in patients with non-alcoholic chronic liver disease in India. JAPI. 1996;44(4):243-5.

12. .Tandon BN, Irshad M, Acharya SK,Joshi YK. Hepatitis virus infection is the major cause of severe liver disease in India. JPN.1991;17(3): 175-9.

13. Amrapurkar DN, Kumar A, Pauk SS, Desai HG. Hepatitis $\mathrm{C}$ virus infection in chronic liver disease. Bombay J Gastroenterology.1992;11(5):162. 